УДК 911.3

DOI 10.31554/978-5-7925-0605-3-2021-52-54

\author{
МЕЖРЕГИОНАЛЬНОЕ ВЗАИМОДЕЙСТВИЕ \\ КАК ФАКТОР РАЗВИТИЯ АЗИАТСКОЙ ЧАСТИ РОССИИ \\ Сысоева Н.M. \\ ИНЦ СО РАН, Институт географии им. В.Б. Сочавы СО РАН, Иркутск, Россия
}

\title{
INTERREGIONAL INTERACTION AS A FACTOR IN THE ASIAN PART OF RUSSIA DEVELOPMENT
}

Sysoeva N.M.

ISC SB RAS, V.B. Sochava Institute of Geography SB RAS, Irkutsk, Russia

Рассматривается роль межрегионального взаимодействия в решении проблем, связанных с охраной и рациональным использованием природных ресурсов, сохранением человеческого капитала и поддержанием качества среды обитания. Байкал является примером централизации решений по сохранению уникальной экосистемы озера и возможности объединения усилий Иркутской области и Республики Бурятия для решения задач социально-экономического развития прибрежных территорий в условиях жесткого природоохранного законодательства.

Ключевые слова: межрегиональное взаимодействие, экономические ассоциации, качество жизни, экологические проблемы, Байкал, местные сообщества.

The role of interregional interaction in solving problems related to the protection and rational use of natural resources, the preservation of human capital and the maintenance of the quality of the habitat is considered. Baikal is an example of the centralization of solutions for the preservation of the unique ecosystem of the lake and the possibility of combining the efforts of the Irkutsk region and the Republic of Buryatia to solve the problems of socio-economic development of coastal territories in the context of strict environmental legislation.

Keywords: Interregional interaction, economic associations, quality of life, environmental problems, Baikal, local communities

В последние годы Российская Федерация активизировала пространственную политику. Была принята Стратегия пространственного развития Российской Федерации [2], пересмотрены состав федеральных округов и макрорайонирование территории страны в целом. Наиболее существенное изменение касается Азиатской части России - передача Забайкальских регионов из Сибирского в Дальневосточный федеральный округ. Соответственно, в новой сетке макрорайонирования исчез и Байкальский регион, всего десятилетие назад бывший объектом федерального стратегического планирования. Однако те стратегии и составленные на их основе программы не принесли Байкальскому региону рывка в социально-экономическом развитии, а новые программы не дают надежды на новое внимание со стороны федерального центра [4].

Между тем, централизация ресурсов, центров принятия решений в территориальном развитии такой огромной страны подавляет действие важнейших для развития регионов факторов, относимых теориями экономического роста к эндогенным - здесь и инклюзивные институты, и укорененный сектор экономики, и повышенное внимание к человеческому потенциалу, которые всегда локализованы. Мы хотим обратить внимание на горизонтальные отношения между регионами, которые могут быть отнесены к числу эндогенных факторов. После 90-х годов XX в., когда субъекты федерации пытались противостоять трансформационному кризису, объединяясь в региональные экономические ассоциации, наступил период, когда повышение степени централизованного изъятия ресурсов и их перераспределения привело к возрастанию конкурентных отношений между соседями за внимание федерального центра, за инвестиции и т.д., и прежние ассоциации фактически распались. Надо сказать, что и федеральный центр не поощрял совместные действия регионов вне его контроля, тем более что укрепление производственных корпораций, особенно государственных, привело к посткризисному расширению производственных связей между предприятиями различных регионов на новой 
основе, формируя единое экономическое пространство страны. Инструментами развития межрегиональных связей со стороны федерального центра стали продвижение крупных инвестиционных проектов, особенно инфраструктурных, и инвестиционная поддержка макрорегионов (наряду с особыми регионами) через федеральные целевые программы.

Однако существует целый спектр проблем, которые не решаются развитием рыночных связей, и, где совместные действия регионов могут быть эффективнее, чем просто централизованное регулирование. Прежде всего, это использование и охрана природных ресурсов, занимающих большие площади, что важно для Азиатской России, поскольку именно это объявляется ее конкурентным преимуществом. В первую очередь, это лесные ресурсы, страдающие от пожаров, не знающих административных границ. Централизация управления лесами не привела ни к адекватному восстановлению качественных древостоев, ни к созданию системы, оперативно ликвидирующей распространение пожаров. Механизмы объединения усилий смежных регионов, заинтересованных в сохранении и приумножении лесных богатств, отсутствуют. В добывающей промышленности ставятся проблемы извлечения сырья из мелких и выработанных месторождений, что требует привлечения так называемых локальных знаний и технологий, учитывающих уникальность и специфичность природных комплексов, и это также может облегчаться взаимодействием заинтересованных региональных сообществ.

Большая часть сибирских и дальневосточных регионов страдает от оттока населения, который нарастает при движении на восток. Здесь множество аспектов возможного объединения соседних регионов для повышения качества жизни и развития человеческого капитала на месте, среди которых и формирование межрегиональных образовательных кластеров, и предлагаемое Стратегией пространственного развития создание крупных межрегиональных объектов социальной сферы. Продолжающаяся второй год пандемия Ковид-19 заставляет обратить внимание, прежде всего, на медицинскую специализацию подобных объектов, поскольку в настоящее время регионы занимаются этой проблемой самостоятельно.

Еще одна сфера важнейшая сфера межрегионального взаимодействия - решение экологических проблем и сохранение среды обитания, поскольку эти проблемы большей частью захватывают несколько регионов.

Данная конференция посвящена Байкалу и его роли в развитии восточной части России. Именно Байкал является главным примером необходимости межрегионального сотрудничества в деле сохранения его уникальной экосистемы. Здесь все решается на основе федерального законодательства, федеральными же структурами. Вместе с тем, эти решения затрагивают интересы населения трех субъектов федерации, формировавших ранее Байкальский регион, особенно Иркутской области и Республики Бурятия. При всей малой связанности хозяйственных систем Иркутской области и Республики Бурятия, за исключением проходящей через них магистральной транспортной инфраструктуры, оба субъекта федерации зависят от Байкала в рамках единой природно-технической системы водосборной территории, самого озера и Иркутского гидроузла. Так, любое решение по уровню озера влияет на благополучие той или иной стороны. Поэтому комплексные проблемы, связанные с озером, его охраной и развитием, должны решаться совместно. Об этом уже много пишется и говорится, но мы остановимся на экономических вопросах, которые с федерального уровня не могут решаться адекватно без позиции заинтересованных регионов. Прежде всего, задача сохранения природного потенциала должна сочетаться с необходимостью повышения благополучия проживающего здесь населения и его участия в принятии решений по среде обитания, что прямо обусловлено целями введения статуса объекта всемирного наследия ЮНЭСКО, одна из которых предписывает обязательное участие местного населения в управлении данным объектом [5; 6]. В нашем случае задачи охраны экосистемы ставятся выше социально-экономического развития местных сообществ, и на федеральном уровне координатором программ по Байкалу является Росприроднадзор.

Один из этих вопросов - рыболовство на Байкале. Невозможно регулировать выловы и стимулировать воспроизводство рыбных ресурсов без координации усилий Иркутской области и Бурятии, поскольку это единый бассейн. Прямые запреты на федеральном уровне стимулируют браконьерство и уход рыболовного бизнеса в тень, при этом потери несут и местные сообщества, и регионы в целом. Много внимания уделяется развитию туризма, при этом, упор делается на его экологической форме, чтобы приспособить задачи экономического развития под требования охраны природных комплексов 
на прибрежных территориях. Однако все федеральные программы игнорируют важнейший для местного населения пляжный туризм, который, с одной стороны, оказывает наибольшее воздействие на прибрежные экосистемы, а с другой стороны, несет значительную социальную функцию для рекреации значительных слоев населения, не имеющего возможности выезжать к морю. Регулирование такого туризма также должны взять на себя прибайкальские регионы, отстаивая право местных сообществ зарабатывать на активных формах отдыха перед внешними претендентами на их организацию.

Можно перечислять множество других сфер деятельности, где требуется горизонтальное взаимодействие субъектов федерации, заинтересованных в социально-экономическом развитии. В условиях замедления экономического роста и фактической стагнации необходим поворот к усилению федеративных начал в отношениях между регионами и федеральным центром, что важно именно для Азиатской России с преобладанием ресурсных экономик. Инициатива этого поворота должна исходить из самих регионов, что требует формирования соответствующих институтов и форм межрегиональной кооперации. В отраслевом плане вопросы полномочия в сфере охраны и рационального использования определенных видов природных ресурсов, как и средства на регулирование такой деятельности, сосредоточены на федеральном уровне, и совместные усилия должны осуществляться в рамках сложившихся форм управления природопользованием. Однако регионы должны захватывать инициативу в решении комплексных проблем, связанных с особенностями территории и населения и выходящими за рамки развития отдельных отраслей, осуществляемых бизнесом или соответствующими федеральными структурами. И Байкал представляет собой именно такое поле для межрегионального взаимодействия в собственных интересах. В качестве институтов межрегиональной кооперации могут выступать совместные органы на базе соответствующих департаментов областных и региональных администраций, которые решают общие задачи в определенных сферах и на определенных территориях, или так называемые межрегиональные государственные корпорации, действующие автономно от администраций, но на основе поставленных целей или принятых совместных программ [1; 3]. И началом такого взаимодействия может стать совместная разработка Иркутской областью и Бурятией программы социально-экономического развития Центральной экологической зоны Байкальской природной территории, которая должна формироваться в интересах и сохранения уникальной природной среды и развития местных поселений в рамках природоохранного законодательства. Разрабатываемый в настоящее время проект совместного научно-образовательного центра Иркутской области и Бурятии должен создать научную основу для реализации таких целей.

Работа выполнена при поддержке гранта РФФИ № 20-010-00990.

\section{Список литературы}

1. Виолин С. И. Корпорация развития как инструмент решения межрегиональных проблем (на примере Байкальской природной территории) // Бизнес. Образование. Право. 2020. № 3 (52). С. 254-259. DOI: 10.25683/VOLBI.2020.52.330.

2. Стратегия пространственного развития Российской Федерации на период до 2025 года. Утв. Распоряжением Правительства РФ от 13.02.2019 №207-p. URL: https://www.economy. gov.ru/material/ directions/regionalnoe_razvitie/strategicheskoe_planirovanie_prostranstvennogo_razvitiya/strategiya_prostranstvennogo_raz vitiya_rossiyskoy_federacii_na_period_do_2025_goda/ (дата обращения: 27.05.2021).

3. Сысоева Н. М., Кузнецова А. Н. Байкальская природная территория в новой сетке марорегионов Сибири // ЭКО. 2019. № 5. С. 89-105. DOI: 10.30680/ECO0131-7652-2019-5-89-105.

4. Тулохонов А. К., Михеева А. С., Бардаханова Т. Б. Еще раз о Национальной программе социальноэкономического развития Дальнего Востока // Пространственная экономика. 2020. Т. 16. № 4. С. 165-179. DOI: $10.14530 /$ se.2020.4.165-179

5. Albert M.T., Richon N., Vinals M. J., Whitecomb A. (eds). Community Development through World Heritage. Paris, UNESCO World Heritage Centre. World Haritage Papers. 2012. No. 31.

6. Brown J., Hay-Edie T. Engaging Local Communities in Stewardship of World Heritage. A methodology based on the COMPACT experience. Paris, UNESCO World Heritage Paper Series. 2014, № 40. 